\title{
Usefulness of Twitter for the Neurointensivist in the COVID-19 Outbreak: The Role of Social Media Platforms in Uncertain Times
}

\author{
Luis R. Moscote-Salazar ${ }^{1}$ Tariq Janjua² Ezequiel Garcia-Ballestas ${ }^{1}$
}

1Department of Neurosurgery, Center of Biomedical Research, Faculty of Medicine, University of Cartagena, Cartagena, Colombia ${ }^{2}$ Critical Care Unit, Regions Hospital, Saint Paul, Minnesota, United States

\section{J Neuroanaesthesiol Crit Care:2020;7:158-159}

Since the start of the coronavirus disease 2019 (COVID-19) pandemic, social networking has increased markedly. ${ }^{1}$ The present list of virtual social networks is extensive, including Skype, YouTube, Zoom, WhatsApp, Signal, Twitter, LinkedIn, and so on. The use of social networks has been an important part of coping with this crisis. ${ }^{1}$ The social networks that initially emerged as strategies for fun and socialization in recent years have become an important part of learning. ${ }^{2}$ Virtual social networks facilitate the construction of knowledge based on personal and common interests. They have progressively occupied an important place in our society. An interesting duality of social networks is the possibility of uniting formal and informal environments in a common goal: continuous learning. The use of social networks facilitates creativity, creation, exchange, and collaboration. ${ }^{3}$ In our world, the possibility of collaboration between remotely located cities and countries opens endless options.

Twitter was launched in March 2006 in California, United States. Currently with more than 300 million active users, it is likely one of the most influential social networks. Continuing medical education can be supported by multiple options and unimaginable twitter applications. Thamman et al commented on the importance of Twitter as an asynchronous learning method, as the use of this social network for journal clubs has grown considerably in recent years. ${ }^{4}$ Among the advantages offered by the use of Twitter are looking for opinions, sharing clinical cases, reviews, publicity webinars, surveys, and networking. ${ }^{5}$

In this new era of COVID-19, the use of social networks for learning will become more relevant. The difficulty with in-person meetings will likely be ongoing in the coming
Address for correspondence Luis Rafael Moscote-Salazar, MD,
Department of Neurosurgery, Center of Biomedical Research,
Faculty of Medicine, University of Cartagena, Cra. 50 \#24120,
Cartagena de Indias, Colombia (e-mail: rafaelmoscote21@gmail.com).

years and forces us to look at the formal and routine use of social media strategies for occupational communication. The demographic component of Twitter also makes it an attractive network: on Twitter everyone has a voice, everyone can comment. ${ }^{4}$ The ability to ask questions and to get countless feedback from a global audience is especially important. In the Twitterverse, some of the most popular in neurocritical care are @SNACCNeuro, @isnacc, @ncsi, @JNeurosurgAnes, @jnaccj, and @neurocritical. Hashtags such as \#Neurocritcare and \#CLaNI are used to categorize messages and facilitate a quick search by users. Nowadays, we cannot have a physical group discussion, such as journal clubs, as we have to maintain social distancing. Social media clubs widen the scope of discussion and allow worldwide participation. The first SNACC journal club discussion (@SNACC @JNeurosurgAnes) was conducted on January 13, 2020.

Twitter polls have great application potential. In real time, we can observe trends: questions that were asked among contacts, people that were mentioned, and hashtags that were used. In addition, the exchange of messages on Twitter helps disseminate scientific knowledge, establish academic ties, and foster scientific collaborations. ${ }^{6}$

With the high virulence of COVID 19, major scientific meetings have become risky events. ${ }^{7}$ COVID-19 will probably remain with us for a long time, which will force us to change our learning strategies and interaction within scientific communities. Finally, the growing influence of social networks in our academic life is indisputable. Combining traditional medical practice with the new culture of digital medicine rechallenges the neurointensivist. ${ }^{8}$
Dol https://doi.org/ 10.1055/s-0040-1714450 ISSN 2348-0548.
(C) 2020. Indian Society of Neuroanaesthesiology and Critical Care.

This is an open access article published by Thieme under the terms of the Creative Commons Attribution-NonDerivative-NonCommercial-License, permitting copying and reproduction so long as the original work is given appropriate credit. Contents may not be used for commercial purposes, or adapted, remixed, transformed or built upon. (https://creativecommons.org/licenses/by-nc-nd/4.0/).

Thieme Medical and Scientific Publishers Pvt. Ltd., A-12, 2nd Floor, Sector 2, Noida-201301 UP, India 
The next few years will witness the impact of social media on medical education in a physically distant society. Ideally, we will be more united with the support of digital tools.

\section{Conflict of Interest}

None declared.

\section{References}

1 Porpiglia F, Checcucci E, Autorino R, et al. Traditional and virtual congress meetings during the COVID-19 pandemic and the post-COVID-19 era: is it time to change the paradigm? Eur Urol 2020. Doi:10.1016/j.eururo.2020.04.018

2 Jalali A, Sherbino J, Frank J, Sutherland S. Social media and medical education: exploring the potential of Twitter as a learning tool. Int Rev Psychiatry 2015;27(2):140-146
3 Thamman R, Gulati M, Narang A, Utengen A, Mamas MA, Bhatt DL. Twitter-based learning for continuing medical education? Eur Heart J 2020. Doi: 10.1093/eurheartj/ehaa346

4 Saenger AK, Berkwits M, Carley S, et al. The power of social media in medicine and medical education: opportunities, risks, and rewards. Clin Chem 2018;64(9):1284-1290

5 George DR, Rovniak LS, Kraschnewski JL. Dangers and opportunities for social media in medicine. Clin Obstet Gynecol 2013;56(3):453-462

6 Desai AN, Patel P. Stopping the Spread of COVID-19. JAMA 2020. Doi: 10.1001/jama.2020.3227

7 Chu LF, Zamora AK, Young CA, Kurup V, Macario A. The role of social networking applications in the medical academic environment. Int Anesthesiol Clin 2010;48(3):61-82

8 McKendrick DR, Cumming GP, Lee AJ. Increased use of Twitter at a medical conference: a report and a review of the educational opportunities. J Med Internet Res 2012;14(6):e176 